\title{
Study on Operation Mode of China's Stadiums
}

\author{
Chunlei Yang, Ting Yang \\ School of Law, Yangtze University, Jingzhou 434023, China \\ ycl114@sina.com
}

\begin{abstract}
Management and operation of large-scale public stadiums is the problem not only for various cities in China but also for various countries in the world. With covers large areas occupied and much more relevant supporting facilities, the stadiums generally are built in suburb areas or rural-urban fringe zones. Though, site selection of stadium in suburb areas is good for holding large-scale sport events successfully while the impact on daily operation of stadium is tremendous. Less foot traffic, incomplete supporting facilities in fringe zones and low consuming ability of residents living in fringe zones cause the difficult operation of stadium and more unused resources. China's stadium shall learn the advanced experience from that of overseas, plan reasonably, investigate in detail and select site carefully in terms of layout and design of stadiums. Stadiums shall be built in areas where more residents live in so as to attract more people to come and watch sports events or participate in activities for fitness conveniently.
\end{abstract}

Keywords: Stadiums, operation mode, administrate.

\section{INTRODUCTION}

Survey shows that in recent years, along with host of various large-scale sports events at home, large number of large-scale stadiums has been built. However three out of them is unused and in the state of loss after the games, which means utilization condition of China's large-scale stadiums remain challenging after the games. The purpose of operating stadiums is to maintain its sustainable development, and operating revenue from it is mainly used for its redevelopment so as to promote function of stadium and realize its social profit. In the daily operation of stadium, the stadiums are free for training of sports team, political activities of provincial and municipal governments, national fitness activities and other large number of public benefit activities. Based on above, in aspects of understanding and operation of stadiums, relevant government departments shall definite the localization of public benefits of stadium and decide the operation mode according to characteristics of public benefit.

Public stadiums, built by nation though investing or raising social funds, under the management of sports administrative department at various levels, used for implementing social physical activities, are physical activities places for board masses to meet their needs of doing physical exercise, enjoying sports activities match, training and match of sportsman. Sports Law and Regulations of Public Cultural and Physical Facilities stipulate: all public stadiums hosted by people's government or social forces, open places and facilities which used for implementing public cultural and sports activities are public cultural facilities. As for definition on size of public stadiums, there is no strict uniform standard so far.

\section{Operational Status of China's LaRge-Scale Stadium}

We know from operational status of sports centers in deferent areas that sports centers in deferent areas have become landmark buildings, therefore the stadiums built for it are undoubtedly valuable wealth left for board masses. Neither host of various large-scale sports events nor large entertaining and commercial performance after the games, nor daily civic physical fitness activities, will positive 
influence is bring. However how to operate and manage sports centers after completion of construction is an urgent task needed to be solved by relevant departments. At present, operation modes of stadiums are as follows:

\subsection{Government Management is Principal}

Government, as owner and manager of stadium, is responsible for management \& development and maintenance of stadium facilities, which is principal operational mode of stadium in China. Government management embodies that China integrate national force to handle affairs under planned economic system. However, under the condition that market economic system has been established in China, the operation and development of stadium managed by government has presented many unfavorable phenomenon, for example, since government lacks deep understanding for sports business resulting in faulty solution in efficiency and method. For this, government shall explore new operational mode so as to adapt to the social development. At present, management mode by legal person has gradually presented its advantage, handing over or entrust all power of management for stadium in a certain time to operational company and non-profit group for managing. The shortcoming of management mode by legal person is that short-term act may happen easily so that public benefit and social profit from large-scale public stadium is hard to be kept. Therefore, pay more attention to prevent such unfavorable phenomenon from happening.

\subsection{Investment Scale of Stadium is Becoming more Larger and Larger While its Maintenance and Re-Utilization is Obviously Insufficient}

At present, Investment scale of large-scale stadium in China is increasingly large such as floor area and the number of seat of stadium are towards the large stale development so as to adapt the rapid economic development and daily demands of board masses. Build stadiums invested millions of Yuan for purpose of holding large-scale sports events; however significant problems appeared in the process of maintenance and re-utilization of such stadiums after game. Since those existing stadiums built through government financial department invest large fund lack reasonable panning and transformation, and successional investment so that some of them has not been repaired for many years and equipped with old-fashioned facilities, resulting in they can't meet the masses' needs on exercise and fitness. Some rooms set in the process of holding matches is unused after matches, causing the waste of resources and occupying the covers area of masses' fitness site. Maintenance and reutilization after match of large-scale stadium is essential means to keep sustainable development of stadiums.

\subsection{Different Operational Modes Bring Various Benefits}

More than millions of stadiums in China have their own operation and management mode. It is exactly because of dual attributes in operation and public benefit that reform orientation of stadiums in China shows polarizations: government emphasizing on operation function boldly carry on reformation of "transforming public undertakings into corporate system", operating stadium in the mode of corporatization while government emphasizing on public activities insists management by public undertaking institutions. Because of this, the two different modes of business operation lead to great difference benefits between different stadiums. Generally, benefit of stadium obtained in the mode of corporatization and under the condition of emphasizing on operation function is comparatively better, which is in state of profits or both ends meet while those stadiums emphasizing on public activities and insisting management by public undertaking generally is in state of loss, and are mainly maintained by financial subsidies from government. Since China lacks experience in management mode of stadiums, resulting in various management modes have their own features and various problems at the same time.

\section{StUdy ON OPERATION Mode OF LARGe-Scale Stadiums}

In the future, the number of stadium in China will be constantly increased, development direction will be gradually explicit, industrial structure will be transformed from public-undertaking-oriented into 
corporatization-oriented, operation will be in the operation mode of globalization, specialization and market-based. All of these will be helpful for solving re-utilization problem after match such as unused stadiums and providing masses with public cultural and physical entertainment services. We believe that operation industry of stadiums will present basing mercerization management and linkage management of multi-service in the future, and corporation related to stadiums will be prosperous and brisk.

\subsection{Promote Reformation of Stadium in Policies and Regulations}

Sports industry, has increasingly closed relations with national economy, is becoming an important force in modern economy and social life. Stadiums are important material base and reliance for development of sports undertaking and sports industry, and is also as a partner of show business, tourist industry and entertainment industry. Government unveils many relevant policies in accordance with development characteristic of sports industry in China, taking market-based operation as orientation, raising money through taking full advantages of various fundraising channels and ways, encouraging social association to participate in operating management activities of stadium, establishing new mode for operating management activities of stadium, leading domestic stadiums to improve utilization efficiency constantly in operation and transform towards mercerization.

Based on consideration of sports undertaking and public service attribute at the same time, conventional "operation by government" and "public benefit-oriented" operation modes of stadium are gradually moving towards "operation-oriented" and "corporation-oriented" operation modes. In recent years, nation unveils policies and regulations related to operation of stadiums from all levels, guiding ownership of stadiums depart from its right of management, and participating in market-based operation mode; directing development direction for operation and management of China's stadiums, guiding stadiums to connect with relevant industries so as to achieve multi-industry integration. Thus it can be seen that policies and regulations shall provide stadiums with corresponding supports and specify development direction of stadiums. New operation and management mode of stadiums can develop favorably only when stadium get support from policies. Thus, government shall fully display its functional role, supporting and leading operation policies related to stadiums.

\subsection{Transform Functional Localization of Stadium, and Implement Diversified and Specialized Operation}

Implement multifunctional development, carry on diversified operating items, and ensure movement of stadiums depending on operation profits. Contents of development are characterized by "sports-based, multi-purpose development". Promote a series of supporting services, such as large performance, expo, masses' fitness and entertainment, commercial development, release of advertising, rent of box, restaurant and accommodation, etc. through sports event, as main industry, form consumer market of sports \& entertainment, and improve usage rate of stadiums through diversified operation so as to obtain overall benefits.

Combining trend of operation and development of stadiums to transform functional localization, gradually realize transformation from stadium-oriented to comprehensive activities venues, such as entertainment, culture and commerce, adjust operation and development strategies of large venues. Relying on resource advantage of venues, actively carry out diversified operating strategy. Provide diversified services for consumers in several industries such as shows, mass entertainment, characteristic commerce industry and form industrial chain of fitness and leisure based on spots industry. Develop potential consumer group from singular sports enthusiast to consumer of all society so as to expand the potential consumer group and take full advantage of resources of stadiums. In addition, diversified operation of stadiums shall base on specialization, through cooperating with specialist agencies and other ways, with aid of special advantage and human resource superiority of specialist agencies, and gradually improve specialized operation level of stadiums. Specialized operation agencies, one the one hand, can improve operation efficiency and benefits of stadiums, on the other hand, can introduce rich contents and resources of large activities for stadiums so as to 
increase operating items of stadiums. The stadium is suggested to cooperate with famous operating agencies of stadiums at home and abroad in the process of operation, such as AEG-the largest sports entertainment group all over the world, SMG-Shanghai Media Group, to learn and referent advanced concept, experience and resources of large activities from operating agencies of overseas stadiums so as to gradually realize specialized operation of stadiums in our city.

\subsection{Select Operation and Management Mode of Stadiums in Correct Way}

"Operation" and "public benefit" are core problems of management mode of large-scale stadiums. Certainly, this is inseparable with the unique mode existed only in China-"division of public-undertakings-oriented and corporations-oriented". As undertaking, government functions and public service shall be main purpose; as corporation, the purpose shall be making benefit. The key point to resolve difficulty facing large-scale stadiums is to solve problems of estate character and management property of stadiums well. According to the existing practice in China, management mode of large-scale stadiums shall be divided from perspective of public undertakings and corporations. However, large-scale stadium shall not be divided lightless into public-undertakings-oriented and corporations-oriented; various influence factors shall be considered so as to determine operation and management mode of large-scale stadiums.

Set detailed evaluation index. Divide stadiums into public-undertakings-oriented and corporations-oriented according to the standard whether large-scale stadiums have condition of making benefit. For corporations-oriented stadiums satisfied the conditions, government shall leave them alone and lead it to carry on independent management, and provides appropriate support, if necessary. For the stadiums satisfied all conditions, commercialized operation can be implemented undoubtedly after overall assessment, and operation benefit shall be as main purpose. Government can prompt stadiums providing public products in way of purchasing services from stadiums so as to ensure stadiums have obtained profits from public services. If corporations-oriented stadiums are forced to provide non-profit public services, then vicious circle will be intensified, and finally resulting in loss of operation and making operation of stadiums difficult to realize sustainable development. Public-undertakings-oriented stadiums shall be contributed by government or raised by society and emphasize on opening stadiums freely. Social benefits brought by stadiums in aspects of increasing urban vitality, improving national people's health level and enriching cultural life are uncountable wealth. However more attention should be paid that operating revenue of public-undertakings-oriented stadiums shall be handed over to government for unified allocation or be input into maintenance and equipment replacement of stadiums.

In accordance with contingency theory, management mode of stadiums shall determine its management means and methods according to internal conditions and external environment of stadiums. Therefore, selection of management mode of stadiums is closely related with objective resources status, and there is no optimal mode, only the most appropriate mode.

\subsection{Actively Develop Market, and Innovate Advertising and Marketing Strategies}

In the process of operation, stadiums in our city shall pay high attention to market development, actively carry on market survey, initially communicate and contact organizer of large activities and prime broker of performance, actively apply and bid holding large activities inside stadium. In process of bidding or undertaking of large activities, stadiums shall gradually change its role as renter of venue, participate in operation of relevant activities and provide various necessary relevant services for organizer.

In the process of operation of large activities, stadiums shall build win-win awareness. It is not only to make profit for stadium itself, only when organizer of large activities make profit, can cooperation between them be promoted and will large activities be introduced inside stadium so as to bring diversified activity resources for operation of stadium. In the process of marketing, stadiums shall deeply develop its resource and product in thought of product research, according to need of market and consumer, on the base of segmenting market for customer group, shall develop product and 
service that can meet different need of consumer at various levels. At the same time, stadium shall segment and cultivate market depending on consumption feature, power of consumption and consumer preference of consumer at various levels so as to form new profit increasing point. Stadium shall pay abundant attention on positive effects of internet, microblog and other emerging media in marketing and skillfully take advantage of network resource to conduct "internet + " marketing so as to expand influence brought by stadium and be convenient for recommending and introducing relevant services.

\section{Bringing up Professional Stadium Operating and Managerial Personnel}

For a long time, the operating personnel of large stadiums have been mainly cadres from sports system, retired athletes and few equipment maintenance professional and technical personnel. Those with real large stadiums management quality and high work efficiency are rare and in unreasonable structures, which has a direct adverse effect on the management and operation benefits of stadium as well as improvement of service level. To bring up professional stadium operating and managerial personnel, we can open to public employment, allowing social talents who pass professional examinations to take management position of the stadium, and differentiate the compensation of operating and managerial personnel based on the division of business stadium and enterprise stadium.

The construction and operation of stadium requires professionals who understand sports rules as well as construction and operation rules of stadium. Unfortunately, these professionals are insufficient and the group is unstable, which directly affected the quality of stadium construction and operation. Therefore, bringing up and introducing high quality professional operation team is a major means to improve operation benefit of stadium. On one hand, higher education institutions and training organizations shall strengthen retraining of existing operating and managerial personnel in stadiums to reinforce their capabilities. In the meantime, professional sports manager (brokerage) company shall be introduced, to allow resource owners to fully supervise their resources and projects, develop a set of scientific operating and managerial approach for comprehensive stadium management and development, and promote and improve the management level of stadium.

\section{Conclusion}

As people's demand for public sports grow and steady implementation of national public service policy, the study of stadium operation and management will draw more attention in the academic world. The trend is that macro management system study will gradually turn into Micro operation mode and content study, general theory study into region, city and even stadium individual case study, and researchers will place more focus on the coordination between stadium operation and management and national economy, social development and national economy policies. In order to take full advantage of the public resources in stadiums and benefit the people, we are committed to explore and establish a series of proper local stadium operation approaches.

\section{ACKNOWLEDGEMENTS}

Jingzhou science and technology development project (2015AD52);

Legislative Research Project of Jingzhou People's Congress Standing Committee (15JZLF02);

Youth Foundation of Yangtze University (2015cqn01);

Society Science Foundation of Yangtze University (2015csy009);

Innovation Foundation of Social Assistance Research Center of Yangtze University (15JZ03).

\section{REFERENCES}

[1] Sean Jones, Why did voters approve the 1998 Denver Broncos Stadium tax initiative? Three competing theories. University of Colorado at Denver, 2007.

[2] Christoph Jacke, Locating Intermediality: Socialization by Communication and Consumption in the Popular Cultural Third Places of the Music Club and Football Stadium. Culture Unbound: Journal of Current Cultural Research, 2009, Vol.1, pp.331. 
[3] Robert C. Trumpbour, The new cathedrals: The sports stadium and mass media's role in facilitating new construction. The Pennsylvania State University, 2001.

[4] Charles Andrew Santo, Beyond the economic catalyst debate: Can consumption benefits justify a municipal stadium investment?. Portland State University, 2005.

[5] Shijian Li, Demand Situation and Countermeasures Research on the Sports Service Products of Rural Residents. Cross-Cultural Communication, 2013, Vol.9 (1), pp. 26-30. 